\section{(Re)escrevendo a história da cidade: o mercado de terras de Passo Fundo (1920 - 1950).}

(Re)writing the history of the city: the land market of Passo Fundo (1920 - 1950).

\section{Pedro Henrique Carretta Diniz*, Caliane Christie Oliveira de Almeida**}

*Arquiteto e Urbanista, mestrando no Programa de Pós-Graduação Stricto Sensu em Arquitetura e Urbanismo da IMED e membro do grupo de pesquisa Teoria e História da Habitação e da Cidade (THAC - IMED), phenriquecd@gmail.com

**Doutora em Arquitetura e Urbanismo, docente no Programa de Pós-Graduação Stricto Sensu em Arquitetura e Urbanismo da IMED e coordenadora do grupo de pesquisa Teoria e História da Habitação e da Cidade (THAC - IMED), caliane.silva@imed.edu.br

\begin{tabular}{ll}
\hline Palavras-chave: & Resumo \\
História Urbana. & Este artigo se insere na temática da história urbana, tomando Passo \\
Loteamentos privados. & Fundo, localizada no noroeste do estado do Rio Grande do Sul, como \\
Vilas Operárias. & objeto de estudo. O objetivo foi analisar o processo de formação e trans- \\
& formação da mencionada cidade, com atenção especial ao período con- \\
& formado entre as décadas de 1920 e 1950, quando diversos loteamentos \\
Keywords: & privados e vilas operárias foram concebidos e transformaram significati- \\
Urban History. & vamente as dinâmicas e o traçado urbano. Este estudo foi baseado em \\
Private allotments. & dados primários, coletados dos arquivos públicos da cidade, e foi dividido \\
Working-class villages & em três etapas: pesquisa bibliográfica, pesquisa documental e pesquisa \\
& iconográfica. Percebe-se, para além das obras de modernização e qua- \\
& lificação empreendidas no espaço urbano, que o mercado de terras de \\
& Passo Fundo ainda é um campo de estudos pouco explorado pela histo- \\
& riografia especializada. Apesar de muitos dos loteamentos e vilas terem \\
dado origem a importantes bairros, especialmente nos anos compreen- & didos no recorte temporal apresentado, tal tema ainda não foi objeto de \\
interesse de pesquisa local. Espera-se que este artigo contribua para o \\
preenchimento dessas lacunas, trazendo novos dados e contribuindo \\
para um maior conhecimento da história urbana de Passo Fundo.
\end{tabular}

\section{Abstract}

This paper takes part of the theme of the city's history, taking Passo Fundo, located in the northwest of Rio Grande do Sul state, as the object of study. The objective was to analyze the process of formation and transformation of the city, with special attention to the period formed between the 1920s and 1950s, when several private allotments and workers' villages were conceived and significantly transformed the dynamics and urban layout. This study was based on primary data collected from the city's public archives, and was divided into three stages: bibliographic research, documentary research and iconographic research. It is noticed, in addition to the modernization and qualification works undertaken in the city, that the Passo Fundo land market is still a field of studies underexplored by specialized historiography. Despite the fact that many of the plored by specialized historiography. Despite the fact that many of the allotments and villages have given rise to important neighborhoods in the city, especially in the years included in the time frame presented, this topic has not yet been the object of interest in local research. It is hoped that this paper will contribute to fill these historiographic gaps, bringing new data and contributing to a better understanding of the urban history of Passo Fundo. 


\section{Linhas introdutórias}

Passo Fundo está localizada no noroeste do estado do Rio Grande do Sul e possui uma população de aproximadamente 200.000 habitantes. É considerada uma cidade de porte médio e um polo regional, devido às relações que estabelece com municípios de sua área de abrangência. Em se tratando das relações verticais, aquelas voltadas ao mercado exterior, destacam-se as atividades em torno do agronegócio e da indústria alimentícia, que compõem um complexo agroindustrial, de ensino e de pesquisa. Acerca das relações horizontais, aquelas estabelecidas com as cidades da região, Passo Fundo se configura como polo de saúde, educação e comércio. Esses três setores são responsáveis por importantes fluxos populacionais, de caráter pendular, entre Passo Fundo e aproximadamente 200 municípios, dentre os quais se destacam Erechim, ljuí, Carazinho, Marau e Soledade (FERRETTO, 2012; IBGE, 2020).

Apesar da representatividade, em relação aos processos de formação e transformação urbana, Passo Fundo ainda é tido como um território pouco explorado. A historiografia local se deteve, sobremaneira, em analisar a ocupação do seu território e a influência europeia nesse contexto, a citar os trabalhos de Parizzi (1983), Gosch (2002) e Ferretto (2012). Ademais, grande parte dos estudos é baseada em relatos orais, nos quais pode-se perceber fragilidades historiográficas que merecem maior aprofundamento e análises, principalmente em relação à história urbana de Passo Fundo na primeira metade do século XX. Torna-se, assim, importante a realização de pesquisas baseadas em dados primários, trazendo a contribuição de novas fontes e, consequentemente, novos olhares para o debate em torno da estruturação e transformações na cidade.

Nos levantamentos de dados primários realizados para a elaboração deste artigo, percebeu-se o anúncio da construção de uma série de novos loteamentos privados, agrupamentos habitacionais edificados por rentistas e vilas operárias, bem como concepção de equipamentos urbanos e a abertura e/ou alargamento de importantes vias que ajudaram a modificar significativamente o cenário passo-fundense, entre os anos 1920 e 1950. Entretanto, a historiografia local desde a década de 1990 vem se concentrando, sobremaneira, na discussão em torno da expansão horizontal de Passo Fundo após a elaboração e outorga do primeiro Plano de Ordenamento e Expansão de Passo Fundo, criado em 1953 e outorgado em 1957, deixando as transformações ocorridas antes deste marco legislativo, em segundo plano. Assim, justifica-se uma atenção especial ao recorte temporal adotado neste trabalho, principalmente no que diz respeito à construção e consolidação de novos bairros.

Vale mencionar que, neste artigo, considerou-se como loteamentos urbanos todas as glebas privadas submetidas a parcelamentos e/ou reagrupamentos, que deram origem a conjuntos de terrenos com menores dimensões, destinados ao mercado de terras. Diferente dos loteamentos, as vilas operárias são tidas como conjuntos habitacionais destinados à população operária, localizados nos arredores das fábricas e indústrias, construídos por meio do investimento de donos de fábricas, industriais ou rentistas. Em linhas gerais, segundo Timm (2015), as vilas operárias surgiram da necessidade de reter os operários perto das fábricas, possibilitando o controle da mão de obra e garantindo melhores condições de vida e de trabalho aos seus funcionários e famílias.

Ressaltando sua importância, a problemática deste artigo envolve a escassez de referências acerca do significativo número de novos loteamentos e vilas operárias que ajudaram a modificar a paisagem urbana passo-fundense no período apresentado, construídos no contexto de modernização da cidade, e que hoje se conformam como importantes bairros de caráter, essencialmente, residencial. Nesse sentido, o objetivo deste artigo foi analisar o processo de formação e transformação da cidade de Passo Fundo, sobretudo, no período compreendido entre os anos 1920 e 1950.

Em relação aos procedimentos metodológicos, este artigo foi realizado em três principais etapas: pesquisa bibliográfica, pesquisa documental geral e pesquisa iconográfica. Na primeira etapa, fez-se o levantamento e a revisão bibliográfica de títulos que abordam a história urbana de Passo Fundo, sua conformação e principais modificações, tendo Parizzi (1983), Gosh (2000), Miranda e Machado (2005), Ferretto (2012), e Tedesco (2015) como principais referenciais teóricos.

A segunda etapa consistiu na pesquisa documental geral de documentos oficiais, legislações relacionadas e periódicos locais da época, referentes ao processo de formação e transformação da cidade. Nesta etapa, foram visitados o Arquivo Histórico Regional de Passo Fundo (AHR/PF) e o Instituto Histórico de Passo Fundo (IHPF), onde foram angariados os principais dados primários desta pesquisa. Dentre os principais periódicos independentes analisados, estão: O Popular (1913 1915); A Época (1921 - 1922); Gazeta (1928); e Diário da Tarde (1946 - 1948). 
Além destes, destacam-se por sua expressividade e representatividade política os jornais: O Gaúcho, pertencente ao Partido Republicano Rio-Grandense (1900 1913); A Voz da Serra (1916 - 1920); e O Nacional, criado em 1925 e ainda em circulação nos dias atuais. Vale destacar que cerca de 2.000 exemplares de periódicos foram levantados até o momento.

Por fim, a terceira e última etapa - pesquisa iconográfica -, também realizada nos supramencionados arquivos públicos, contribuiu para identificação e o mapeamento das principais ações que modificaram a paisagem urbana passo-fundense dentro do recorte temporal adotado. Espera-se que este artigo colabore para um maior debate em torno do processo de transformação da cidade de Passo Fundo, trazendo novos elementos, fontes e atores, nesse sentido.

\section{A Estrada de Tropas e o início da ocupação de Passo Fundo}

O processo de ocupação da região onde atualmente está localizada a cidade de Passo Fundo data das primeiras décadas do século XIX. Naquela época, o território servia principalmente como passagem dos chamados tropeiros - condutores de tropas e de alimentos, principalmente charque (carne seca) - do sul do estado do Rio Grande do Sul para a região sudeste do país, em especial para São Paulo. Esse trajeto ficou conhecido como Estrada de Tropas ou Caminho dos Paulistas. Hoje em dia, essa estrada se conforma como a principal via arterial da cidade, a Avenida Brasil (PARIZZI, 1983).

Consolidada como importante ponto de passagem e pousada por parte dos tropeiros, a localidade começou a chamar atenção do Governo Imperial, que concedeu ao militar Manoel José das Neves - popularmente conhecido como Cabo Neves uma gleba correspondente a 17.724 hectares, em fins da década de 1820 (PARIZZI, 1983). Naquele período, o território em questão era habitado pelos indígenas das tribos Tapes e Caingangs. Neves, considerado o primeiro colonizador da região, trouxe consigo de São Paulo sua família, escravos e gado, e implantou uma fazenda pastoril e agrícola. No entorno da fazenda, outras famílias se instalaram, fato que culminou no surgimento da vila de Passo Fundo em meados daquele século (FERRETTO, 2012).

Em linhas gerais, os povoados ao longo do século XIX necessitavam da figura de, ao menos, uma autoridade administrativa, judicial ou fiscal, para serem reconhe-
(Re)escrevendo a história da cidade: o mercado de terras de Passo Fundo (1920 - 1950) cidos como distritos. No caso de Passo Fundo, Joaquim Fagundes dos Reis, também advindo de São Paulo, tornou-se a primeira autoridade que se tem notícias. Ele foi nomeado, por meio da Comandância Militar de São Borja, Inspetor de Quarteirão e, alguns anos depois, conquistou o cargo de Juiz de Paz. Assim, em 1834, a pequena ocupação passou a integrar o domínio da cidade de Cruz Alta, conformando-se como o seu $4^{\circ}$ Distrito, juntamente à Palmeira das Missões, São Pedro e Santa Maria (PARIZZI, 1983).

Em 1847, mais de uma década após a ascensão de Passo Fundo à distrito de Cruz Alta, as obras da primeira capela da localidade foram finalizadas, e o então distrito passou a contar com a presença de um eclesiástico. Na ocasião, foi consolidada a Freguesia de Passo Fundo, sob a denominação de Nossa Senhora da Conceição Aparecida (PASSAMANI, 2012). Naquele período, a maior parte das edificações existentes estava implantada ao longo da referida Estrada de Tropas, além de pontuais edificações distribuídas de forma dispersa nos seus arredores e nas proximidades do Arroio do Chafariz; principal ponto de abastecimento de água da cidade à época (Figura 1). Nas palavras de Miranda e Machado (2005), a predominância de ocupações a oeste da capela ocorreu por três principais fatores: a proximidade com - Arroio do Chafariz, a topografia da área (mais plana e propícia para a construção) e a presença de mata nativa ao sul e ao norte, protegendo a freguesia de possíveis invasões.

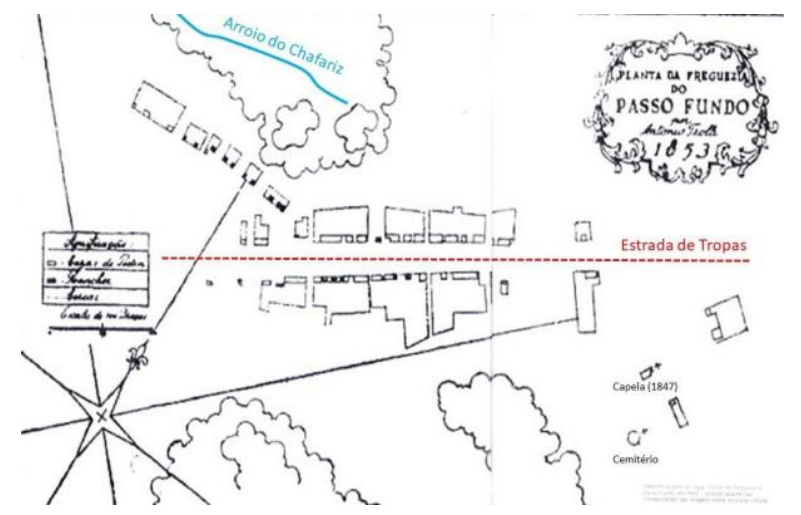

Figura 1: Planta da Freguesia de Passo Fundo (1853), onde pode-se observar a Estrada de Tropas como o eixo estruturador, bem como o Arroio do chafariz, a Capela e o cemitério. Fonte: $\mathrm{Pa}$ rizzi (1983, p.52), adaptação própria. 
A emancipação política de Passo fundo ocorreu em 1857, por meio da outorga da Lei provincial $n^{\circ} \mathbf{3} 40$ de 28 de janeiro, a partir da determinação do brigadeiro Jerônimo Coelho, presidente da Província do Rio Grande do Sul à época. Na ocasião, para a recém-criada cidade de Passo Fundo, foram empossados sete Conselheiros, cargo similar ao de vereador na atualidade (PARIZZI, 1983).

Até o final do século XIX, o desenvolvimento de Passo Fundo ainda era pouco expressivo e se deu paulatinamente. Foi a partir da década de 1890 que os quadros citadino e econômico foram consideravelmente alterados, com a intensificação dos fluxos migratórios interno e externo (população rural e imigrantes europeus) e a construção da linha férrea. Em se tratando do primeiro aspecto, os imigrantes, sobretudo alemães, italianos e poloneses, se instalaram na cidade e ocuparam espaços privilegiados no setor econômico, inserindo-se no comércio local ou como proprietários de terras (DAL AGNOL, 2018; PASSAMANI, 2012).

\section{O som da locomotiva anunciando a chegada do progresso}

O principal marco para o desenvolvimento local e projeção regional de Passo Fundo em fins do século XIX foi a construção da linha férrea, no ano de 1898. A partir de então, foi possível o escoamento dos produtos fabris. À época, a base econômica da cidade era derivada do abate de suínos, da plantação de erva-mate e trigo, bem como da exportação de madeira, fato que se manteve até meados do século XX (WICKERT, 2002).

A ideia da criação da linha férrea Tronco Norte Gaúcha, passando por Passo Fundo, começou a ganhar força ainda no final do período imperial (1822 - 1889), quando houve a necessidade de ligar a cidade de Itararé, no sul do estado de São Paulo, com a cidade de Santa Maria, no centro do estado do Rio Grande do Sul, facilitando o escoamento de produtos entre o Sul e os maiores mercados consumidores do país, no Sudeste. No ano de 1891, o projeto da linha férrea foi aprovado, o que possibilitou transformar Santa Maria em um centro ferroviário estadual (TEDESCO, 2015).

${ }^{1}$ Mais precisamente, até 1918, Passo Fundo já possuía 7 praças públicas. Ademais, os dois maiores hospitais da região, O Hospital de Clínicas e o Hospital São Vicente de Paulo, foram fundados em
(Re)escrevendo a história da cidade: o mercado de terras de Passo Fundo (1920 - 1950)

A partir da construção da linha férrea, a cidade de Passo Fundo se desenvolveu econômica, social, cultural e urbanisticamente. Parizzi (1983) observa que, em fins do século XIX e durante as primeiras décadas do século XX, já se registrava na cidade a existência de escolas públicas e privadas, clubes, hospitais, cinema, praças, açougues, alfaiatarias, escritórios de advocacia, bares, curtumes, hotéis e pensões, olarias, padarias, farmácias, fotógrafos, sapatarias, marcenarias, entre outros estabelecimentos comerciais e de serviço ${ }^{1}$. Desse modo, o período em questão correspondeu a uma fase de profundas mudanças na estrutura e na paisagem da cidade e da região, principalmente devido ao novo cenário econômico que se estabeleceu e ao crescimento populacional resultante dele.

Nesse contexto de significativas mudanças, em 1919, o engenheiro sanitarista Saturnino de Brito foi convidado pelo então governador do estado do Rio Grande do Sul, para a realização de um plano de saneamento e expansão urbana para Passo Fundo (Figura 2). Como observado por Junior (2018) e Junior, Almeida e Kujawa (2020), a proposta do engenheiro revelou sua preocupação com as questões ambientais, em especial com o curso dos rios, o aproveitamento natural das forças hídricas e a educação ambiental da população. Ademais, Saturnino de Brito se dedicou ao embelezamento da cidade, considerando a proteção do patrimônio natural com a crescimento urbano. Esse plano não foi implantado pela municipalidade, revelando que, em muitos casos, o "(...) obstáculo para a construção de uma cidade melhor não [era] a falta de conhecimento, mas o consentimento em não aplicar esse conhecimento" (JUNIOR, 2018, p.54, grifo nosso).

A primeira vila operária edificada em Passo Fundo que se tem notícias também foi construída graças à implantação do eixo ferroviário na cidade. A Vila dos Ferroviários, construída pela Viação Férrea do Rio Grande do Sul (VFRGS), era um conjunto habitacional de pequeno porte, composto por algumas casas destinadas aos funcionários graduados da VFRGS, localizadas aproximadamente a 500m da estação férrea, e uma casa isolada, destinada ao engenheiro-chefe, ao lado da referida estação. Não se sabe com exatidão o número de unidades habitacionais, mas em fotos antigas pode-se constatar que eram em torno de 6 unidades habitacionais

1914 e 1918, respectivamente, demonstrando a importância das primeiras décadas do século XX para a configuração da Passo Fundo atual (FERRETTO, 2012). 
(Figura 3). Atualmente, apenas três casas permanecem edificadas e em uso, além da residência do engenheiro-chefe, que está em situação de abandono.

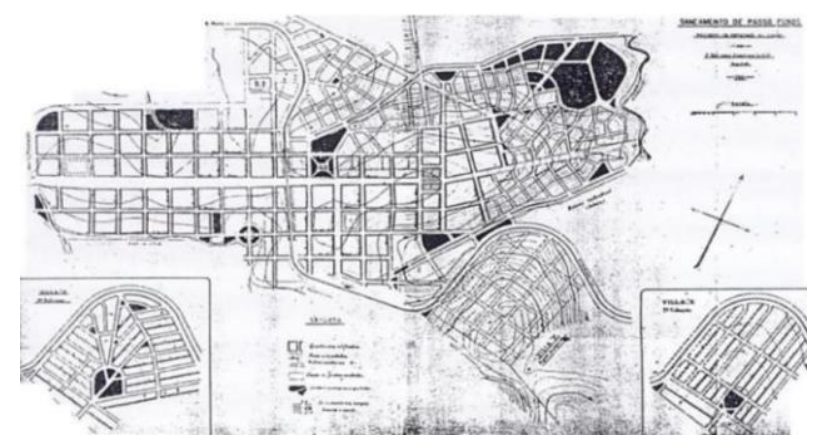

Figura 2: Plano urbanístico de Saturnino de Brito para Passo Fundo (1919). Fonte: MINISTÉRIO..., 1943 .

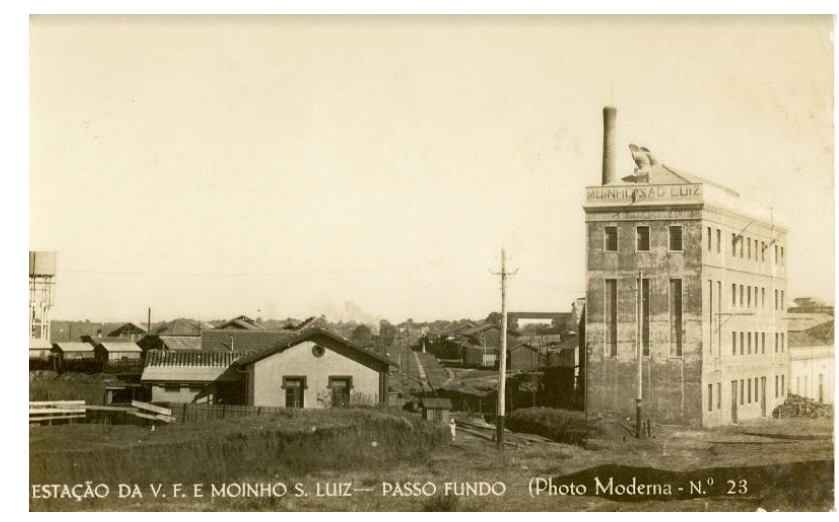

Figura 3: foto parcial da Vila dos Ferroviários, onde pode-se observar as casas e o moinho em primeiro plano, bem como os trilhos ao centro e a caixa d'água aos fundos (s/d). Fonte: INSTITUTO HISTÓRICO REGIONAL/PF (2020).

\section{Os loteamentos privados impulsionando o desenvolvimento}

Nos anos 1920, o traçado orgânico da ferrovia, que fora construída duas décadas antes, já dividia a malha urbana da cidade em duas partes, sendo a porção sudoeste
Pedro Henrique Carretta Diniz e Caliane Christie Oliveira de Almeida

(Re)escrevendo a história da cidade: o mercado de terras de Passo Fundo (1920 - 1950)

a mais ocupada. Ademais, a ferrovia propiciou a instalação de armazéns e madeireiras ao longo de seu traçado, inclusive dentro da área urbana, conformando-se como um eixo "dinamizador da urbanização e uma determinante fundamental à localização das indústrias no início do século XX" (FERRETTO, 2012, p.68).

Em 1920, os terrenos de um novo loteamento particular situado a sudeste da Estrada dos Tropeiros, numa área especificada como de expansão no Plano de Saturnino de Brito (JÚNIOR, ALMEIDA e KUJAWA, 2020), um dos primeiros encontrados nos levantamentos documentais, começaram a serem anunciados nos jornais locais da época. Tratava-se da Vila Rodrigues, implantada nos arrabaldes da cidade, tendo sido financiada por iniciativa de seu proprietário, o Sr. Faustino Rodrigues:

Estão sendo construídas belas vivendas particulares, no centro da praça já ajardinada [atual Praça Capitão Jovino], existe um quiosque montado com todo o capricho, onde se encontram finas bebidas, cerveja, chopp, doces e frios. [...] um passeio à Vila Rodrigues, aos domingos, é uma suprema demonstração de gosto de nossa elite (A VOZ DA SERRA, 1920, p.03, grifo nosso).

Por mais que esta nova área, tenha sido ocupada no início dos anos de 1920, apenas em 1927 foram iniciados os trabalhos para a abertura da rua de ligação do novo empreendimento à cidade; possibilitando a sua efetiva ocupação e estabelecendo o marco inicial de ocupação do bairro homônimo. A obra consistia no prolongamento da atual Rua General Canabarro, atravessando a linha férrea (O NACIONAL, 1927), consolidando a atualmente denominada Rua Coronel Pelegrini.

Em fins da década de 1920, outros quatro novos loteamentos foram inaugurados em Passo Fundo. São eles: Vila Cruzeiro, Vila Petrópolis, Vila Carmem e Vila Costa. A Vila Cruzeiro, mais especificadamente, começou a ser implantada em meados de 1928, quando os empresários Herminio Silveira e Joaquim Silveira compraram de Faustino Rodrigues uma gleba para a concepção desse novo loteamento ao lado da Vila Rodrigues (O NACIONAL, 1928).

Outro novo loteamento foi implantado na porção nordeste da cidade, em 1928. Por meio de anúncios publicados nos periódicos locais em circulação na época, a Companhia Predial LTDA. comunicou aos interessados a venda de terrenos e chácaras na recém-criada Vila Petrópolis, "antiga chácara do Coronel Gervásio, junto aos 
limites urbanos, à margem do Rio Passo Fundo, em frente à Avenida Capitão Jovino, prolongamento da Avenida Brasil [...]" (O NACIONAL, 1928, p.04).

No ano de 1929, mais dois loteamentos foram aprovados e anunciados nos principais jornais da cidade. O primeiro deles foi a Vila Carmen, localizada próxima à Estação Ferroviária. A gleba possuía $700.000 \mathrm{~m}^{2}$ e estava sendo loteada pela Empresa Lima Costa e Cia. O outro loteamento, por sua vez, estava sendo aberto pela mesma empresa ao lado do bairro Boqueirão e fora denominado de Vila Costa (O NACIONAL, 1929).

Diante do crescente cenário de expansão urbana da cidade de Passo Fundo na década de 1920, sobretudo de sua porção norte, o poder público municipal viu a necessidade de ordenar o crescimento e uso do solo urbano da cidade, mantendo as diretrizes higiênico-sanitárias defendidas na época em diferentes cidades do país (ALMEIDA, 2007). Nesse contexto, foi elaborado um novo Código de Posturas para Passo Fundo, promulgado pelo Ato no 402 de 1924. Em síntese, o mencionado Código tratava de diretrizes e definições para: domínios municipais e limites urbanos; diversões públicas; veículos e cavaleiros; tropas e animais; construções e reconstruções; calçadas e andaimes; edifícios em ruínas; muros e cercas; moléstias contagiosas; matadouros e açougues; cemitérios e sepulturas; comércio e indústria; concessão de terrenos municipais; extinção de formigas; caça e pesca; propriedade urbana; propriedade agrícola e pastoril; estradas e caminhos; jogos e carreiras; tranquilidade pública; e disposições gerais (O NACIONAL, 1925).

Dentre os itens especificados no Código de Posturas de 1924, destaca-se aquele em relação às construções e reformas, que passou a exigir, a partir de então, a aprovação da Intendência Municipal para qualquer obra dentro dos limites urbanos executadas. $O$ documento ainda estabeleceu as dimensões mínimas necessárias para os recuos frontais e laterais para as novas edificações (mínimo 1,5 m). No item Calçadas e Andaimes foi determinada, dentre outros aspectos, quais os materiais que poderiam ser utilizados para os passeios e calçamento das vias, que passaram ser obrigatórios sob pena de multa (O NACIONAL, 1925).

Para os edifícios em ruínas, ficou determinado que, após vistorias de profissionais qualificados, todos os prédios que estivessem em perigo de desabamento seriam demolidos e as despesas da demolição seriam cobradas do proprietário. Em relação ao comércio e aos estabelecimentos industriais, por fim, a Lei proibiu a
(Re)escrevendo a história da cidade: o mercado de terras de Passo Fundo (1920 - 1950) construção de fábricas e indústrias que poderiam causar danos à população no centro da cidade, além de determinar os impostos necessários para o funcionamento de todos os estabelecimentos comerciais e industriais no município (O NACIONAL, 1925).

Naquele período, muitas novas edificações estavam sendo construídas em meio ao surgimento dos novos bairros e da promulgação do referido Código de Posturas. De acordo com dados cedidos ao jornal O Nacional pelo engenheiro municipal da época, Octacílio Ribas, entre janeiro de 1925 e maio de 1926, a Seção de Obras Públicas de Passo Fundo emitiu licenças para a construção de 46 casas de alvenaria, 10 casas mistas (alvenaria e madeira), 82 casas de madeira e 36 reformas, totalizando 174 novas obras em 17 meses (O NACIONAL, 1926).

Além dessas edificações, em 1926 foi inaugurado Quartel do Exército (Figura 4), na Rua Teixeira Soares. À época, as três edificações que compunham o complexo militar contrastavam em tamanho com as demais construções do entorno (FERRETTO, 2012). O Matadouro Público de Passo Fundo, esperado há mais de 10 anos pela população, também foi construído naquele ano. Na ocasião de sua inauguração, em 12 de outubro de 1926, mais de 1.000 pessoas participaram de um churrasco festivo (O NACIONAL, 1926).

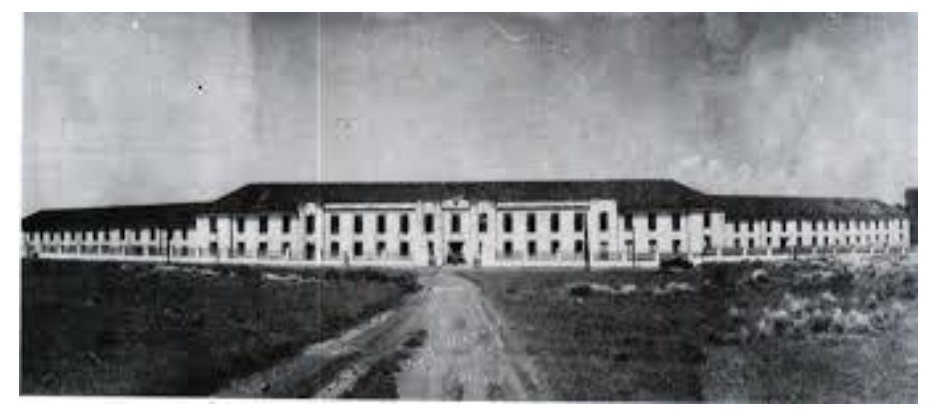

Figura 4: Quartel do Exército - Passo Fundo (s/d). Fonte: Instituto Histórico Regional/PF (2020).

Em se tratando das obras de melhoramentos urbanos, a primeira menção a melhoramentos empreendidos na então Avenida Mauá (atual Avenida Presidente Vargas) ocorreu em 1929. Tratava-se da desobstrução e do calçamento de um trecho dessa 
via arterial que já possuía, à época, grande movimento de comerciantes devido à sua proximidade com a Estação Ferroviária (O NACIONAL, 1929).

Observa-se, assim, que a década de 1920 representou um período de significativas transformações urbanas em Passo Fundo (Figura 5), principalmente em virtude da aprovação e abertura de loteamentos, financiados especialmente pela iniciativa privada. Atualmente, esses loteamentos se conformam como grandes bairros da cidade, a citar: a Vila Rodrigues, a Vila Cruzeiro e Petrópolis. Outros, devido à localização e à vocação inicial (loteamentos voltados, especialmente, à classe operária), permaneceram pouco desenvolvidos e não se destacam, quanto ao porte, no cenário citadino, como a Vila Carmen e a Vila Costa. Com exceção da Vila Costa, cuja localização não foi identificada nos dados levantados nesta pesquisa, curiosamente, todos os mencionados loteamentos se consolidaram e tiveram seus nomes preservados.

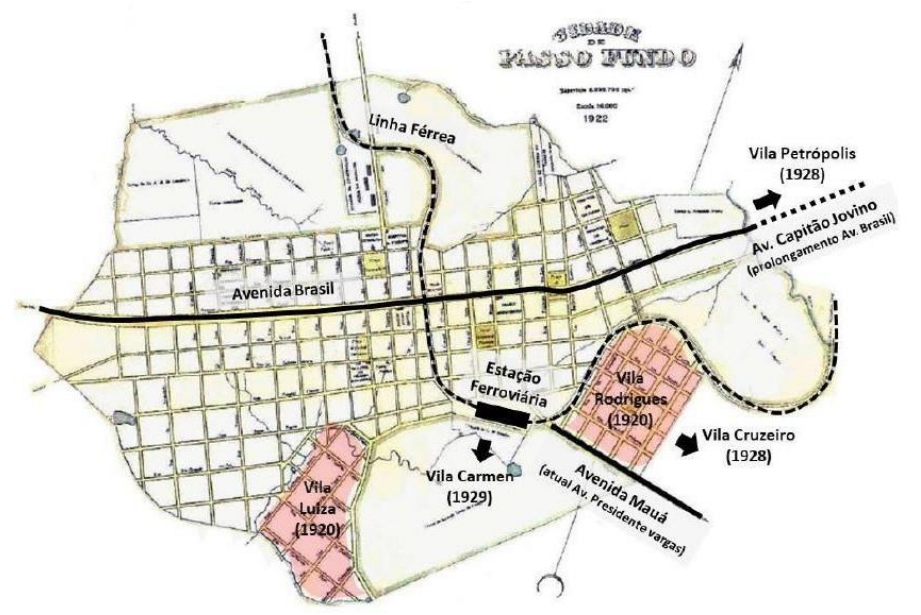

Figura 5: Transformações urbanas de Passo Fundo ao longo da década de 1920. Fonte: Gosch (2002, p.26), adaptado pelo autor.

A expansão e modernização urbana observadas a partir da abertura dos mencionados loteamentos privados, principalmente na década de 1920, continuou a passos largos nos anos seguintes. Nesse sentido, o relatório de governo do Prefeito Mário
Pedro Henrique Carretta Diniz e Caliane Christie Oliveira de Almeida

(Re)escrevendo a história da cidade: o mercado de terras de Passo Fundo (1920 - 1950)

Menegaz (1956-1960) colocou que apenas entre os anos 1938 e 1939, houve o registro de 151 novos prédios edificados, sendo a maioria em alvenaria (RELATÓRIO..., 1969). Diante desse contexto, novos bairros foram criados, dentre os quais se destacam a Vila Vera Cruz (década de 1930), a Vila Santa Terezinha (hoje em dia Vila Fátima - década de 1930), a Vila Santa Maria (década de 1930), a Vila São João (década de 1930) e a Vila Vergueiro (década de 1940) (Figura 6).

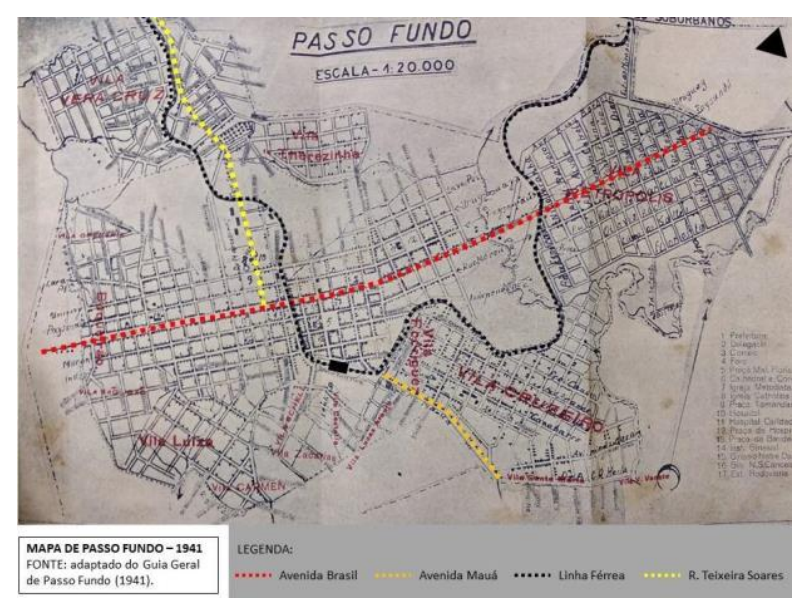

Figura 6: Mapa de Passo Fundo no ano de 1941, com destaque para a Avenida Brasil, Avenida Mauá, linha férrea e Teixeira Soares, representando os principais eixos indutores de crescimento em meados no Século XX. Fonte: Guia Geral de Passo Fundo (1941, p.64), adaptado pelo autor.

Na década de 1950, mais de 30 anos após a elaboração do Plano de Saneamento de Saturnino de Brito (1919), o primeiro Plano de Expansão e Ordenamento Urbano de Passo Fundo foi elaborado, em 1953. Esse plano foi formulado por uma equipe de arquitetos e urbanistas liderada por Demétrio Ribeiro, Edgar Graeff, Eduardo Paiva (engenheiro) e Francisco Macedo, e foi sancionado em 1957 (GOSCH, 2002).

Em linhas gerais, o Plano de 1953 tinha como objetivo principal orientar o crescimento urbano e alocar grandes equipamentos de uso coletivo, tais como: o centro cívico, o estádio, o cemitério municipal, uma futura universidade e o mercado regional. Quanto ao zoneamento, a cidade de Passo Fundo ficou subdividida em zona central, zona comercial atacadista e zona comercial varejista (GOSCH, 2002). 
A partir da década de 1950, a Vila Petrópolis, criada em fins dos anos 1920, passou a se conformar como o principal sentido de crescimento urbano à leste; enquanto que a Vila Cruzeiro e a Vila Vera Cruz, criadas nos anos 1920 e 1930, respectivamente, se tornaram importantes eixos de expansão no entorno das atuais Avenida Mauá (atual Presidente Vargas) e Rua Teixeira Soares: "Esses caminhos viabilizaram a ocupação das porções norte e sul da cidade e até hoje, juntamente à Avenida Brasil, constituem as três vias intraurbanas mais importantes de Passo Fundo" (FERRETTO, 2012, p. 69)

Vale destacar, ainda, que nesse período Passo Fundo tinha uma população de, aproximadamente, 100.000 habitantes. Destes, 32.000 viviam na zona urbana, representando $32 \%$ da população (Tabela 1).

Tabela 1: Evolução populacional de Passo Fundo (1854 - 1960). Fonte: IBGE, 2020.

\begin{tabular}{|c|l|l|l|l|l|}
\hline ANO & $\begin{array}{c}\text { POPU- } \\
\text { LAÇÃO }\end{array}$ & RURAL & $\begin{array}{c}\% \\
\text { RURAL }\end{array}$ & $\begin{array}{c}\text { UR- } \\
\text { BANA }\end{array}$ & $\begin{array}{c}\text { \% UR- } \\
\text { BANA }\end{array}$ \\
\hline 1857 & 7.586 & $\begin{array}{l}\text { Indis- } \\
\text { ponível }\end{array}$ & $\begin{array}{l}\text { Indis- } \\
\text { ponível }\end{array}$ & $\begin{array}{l}\text { Indis- } \\
\text { ponível }\end{array}$ & $\begin{array}{l}\text { Indis- } \\
\text { ponível }\end{array}$ \\
\hline 1900 & 21.374 & $\begin{array}{l}\text { Indis- } \\
\text { ponível }\end{array}$ & $\begin{array}{l}\text { Indis- } \\
\text { ponível }\end{array}$ & $\begin{array}{l}\text { Indis- } \\
\text { ponível }\end{array}$ & $\begin{array}{l}\text { Indis- } \\
\text { ponível }\end{array}$ \\
\hline 1920 & 65.000 & 59.000 & 90,77 & 6.000 & 9,23 \\
\hline 1940 & 80.138 & 59.554 & 74,31 & 20.584 & 25,69 \\
\hline 1950 & 101.887 & 69.658 & 68,37 & 32.229 & 31,63 \\
\hline 1960 & 96.179 & 42.620 & 45,74 & 50.559 & 54,26 \\
\hline
\end{tabular}

Como pode-se observar, a população de Passo Fundo foi crescendo paulatinamente desde a sua emancipação, em 1857, até o ano de 1900. Quando são observados os dados da primeira metade do século $\mathrm{XX}$, o crescimento populacional se mostrou significantemente maior: em torno de $500 \%$ entre 1900 e 1950, mais precisamente. Ao longo da década de 1950, devido a emancipação política de alguns distritos de Passo Fundo, a população decresce de 101.887, chegando a 96.179 habitantes em 1960. Entretanto, os dados demográficos deste ano demonstram,
(Re)escrevendo a história da cidade: o mercado de terras de Passo Fundo (1920 - 1950) pela primeira vez, a prevalência da população urbana sobre a população rural: $54,26 \%$ dos passo-fundenses moravam na zona urbana do município à época.

\section{As vilas operárias como consequência da urbanização acelerada}

Conforme observado em diversas cidades, no contexto de intensificação do processo de industrialização do Brasil acompanhando o projeto nacional desenvolvimentista, a década de 1950 marcou o início de um período de significativo desenvolvimento para Passo Fundo. Concomitante à outorga do já mencionado Plano de Ordenamento e Expansão (1957), a então conhecida Avenida Mauá e, por consequência, a região sudeste da cidade, conformada pelo atual Bairro São Cristóvão, ganharam maior importância nas dinâmicas urbanas e se tornaram um importante vetor de crescimento (GOSCH, 2002).

Foi assim que, em meados do século XX, a Avenida Mauá se tornou o principal vetor de crescimento urbano no sentido sudeste da cidade, estando ligada diretamente à consolidação do bairro São Cristóvão, o maior de Passo Fundo atualmente, que ocorreu a partir dos anos 1950 com a implantação de fábricas ligadas ao setor do agronegócio. Além de ser pouco ocupada à época, a decisão de tornar a região um eixo indutor de crescimento se justifica pela proximidade com a RS-324, que dá acesso à importantes centros urbanos no contexto regional, tais como Marau, Serafina Correia, Nova Prata, Bento Gonçalves e Caxias do Sul (GOSCH, 2002).

Nesse contexto, diversas empresas começaram a se instalar na região do Bairro São Cristóvão, que se tornou berço das mais importantes fábricas da cidade, a citar o Frigorífico Z. D. Costi, o Frigorífico Planaltina, a Semeato e as fábricas de refrigerantes da Pepsi-Cola e dos Irmãos Bernardon. Nos dois primeiros casos, os proprietários decidiram criar conjuntos habitacionais para reter, controlar e proporcionar melhores condições de vida e trabalho aos seus funcionários, e assim surgiram as vilas operárias do Frigorífico Z. D. Costi e do Frigorífico Planaltina, as duas maiores da cidade (DINIZ; ALMEIDA, 2018).

Vale lembrar que o conceito de vila operária consiste em conjuntos residenciais, construídos nos centros urbanos ou arrabaldes, dotados ou não de equipamentos de uso coletivo e de lazer, composto por moradias geralmente perfiladas que podiam ocupar um ou dois lados de uma via principal, com ou sem saída. Segundo Almeida (2012), as vilas operárias surgiram como uma forma de organização que 
se consolidou como resposta à falta de ordem, higiene e decência, características atribuídas às moradias proletárias em fins do século XIX. Em linhas gerais, esses conjuntos eram viabilizados pelos investimentos dos donos de fábricas e industriais, que os construíam para abrigar os próprios funcionários. Em outros casos, investidores externos - à época chamados de rentistas -, percebiam a necessidade de promover moradias aos operários de alguma fábrica e, assim, financiavam a construção de vilas nos arredores dos prédios fabris (CORREIA, 2001; TIMM, 2015).

A vila operária do Frigorífico Z. D Costi (Figura 7) foi a primeira a ser implantada na região sudeste da cidade de Passo Fundo, às margens da então Avenida Mauá (MENÇÃO..., 1979). O matadouro foi inaugurado em 1948 e sua vila operária foi construída em três etapas, conforme a capacidade fabril e o número de funcionários ia aumentando. À época, a localidade era um descampado e a referida avenida nem possuía calçamento. Essa falta de infraestrutura revela a importância da Vila Operária Z. D. Costi para a construção do parque habitacional na localidade (TEDESCO; SOUZA, 2016).

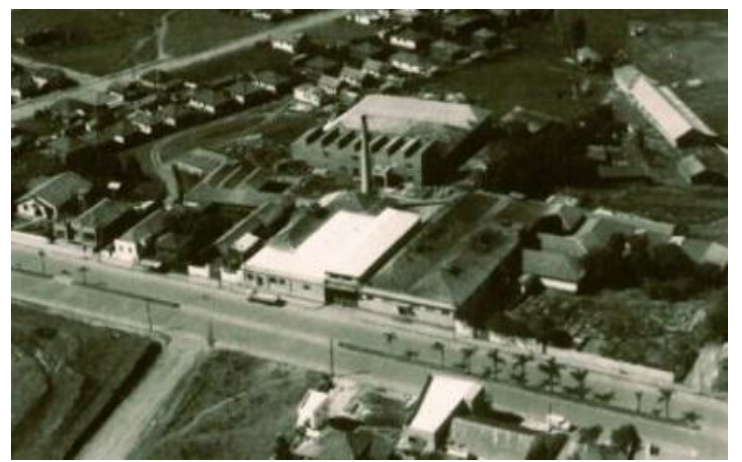

Figura 7: Foto aérea do Frigorífico Z. D. Costi na década de 1950), onde pode-se observar parte da vila operária ao lado esquerdo dos prédios fabris e a Avenida Mauá já pavimentada. Fonte: Costi e Ribeiro, 2003, p.3.

Segundo Diniz e Almeida (2018), a primeira etapa da Vila foi construída em 1948, ao lado esquerdo do Frigorífico, e possuía 20 casas. A segunda, também com 20 casas, foi construída em meados dos anos 1950 e ficava localizada atrás do frigorífico. Em ambos os casos, as vilas eram conformadas por uma via principal, sem
(Re)escrevendo a história da cidade: o mercado de terras de Passo Fundo (1920 - 1950) saída, com casas perfiladas em ambos os lados. As casas eram padronizadas e pertenciam aos donos do frigorífico (Figura 8).

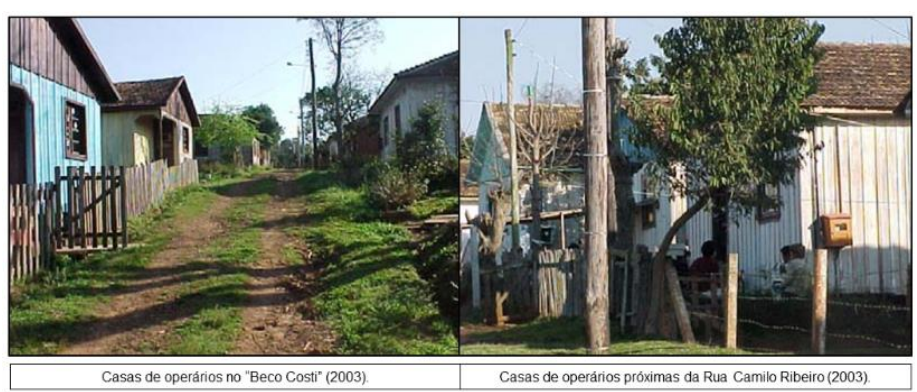

Figura 8: Casas operárias de propriedade Z. D. Costi (2003). Fonte: Costi e Ribeiro (2003, p.10).

A terceira etapa, por sua vez, foi construída por um investidor externo, chamado André Rebecchi, no ano de 1959. Acredita-se que, aos moldes do que ocorria em diversas outras cidades e diante do crescimento do frigorífico ao longo da década de 1950, o mencionado rentista decidiu construir a terceira etapa da vila ao lado da fábrica, utilizando-se, inclusive, do nome Z. D. Costi para denominar o seu loteamento. A gleba em questão foi desdobrada em 76 terrenos menores, de diferentes tamanhos, estruturados por meio de uma via principal que foi denominada Rua Leopoldo Vila Nova. Destaca-se que esta terceira etapa não foi sequer citada por nenhum autor que abordou o processo de formação e transformação do Bairro São Cristóvão, ou a história da Família Costi e dos frigoríficos em Passo Fundo e região. A identificação deste loteamento só foi possível por meio dos levantamentos documentais realizados, nos quais se encontrou o Ato de Aprovação (Ato nํำ 7/1959).

Diferentemente das duas etapas anteriores, as casas da terceira etapa não eram padronizadas e pertenciam aos seus moradores, que as construíam conforme suas necessidades e gostos pessoais. É possível afirmar, assim, que mais de 10 anos após a inauguração do frigorífico, alguns funcionários já possuíam condições financeiras de comprar a própria casa. Após a falência do frigorífico, que se deu em 1993, todos os prédios fabris e as duas primeiras etapas da vila passaram a pertencer a massa falida da empresa, e foram demolidos em 2014 para dar lugar ao canteiro de obras de um shopping center (DINIZ; ALMEIDA, 2017). A terceira etapa, por não 
pertencer aos proprietários do frigorífico, não foi demolida para dar lugar ao mencionado empreendimento, mas se encontra descaracterizada por meio das mudanças socioespaciais ocorridas ao longo dos anos e impulsionadas, inclusive, pela construção do centro comercial.

Outro importante Frigorífico e sua vila operária que se instalaram na região do atual bairro São Cristóvão foi o Planaltina (Figura 9). O processo de criação dessa fábrica, iniciou em outubro de 1956, quando o empresário Félix Sana se desligou da sociedade a qual fazia parte no Frigorífico Z. D Costi e fundou a Indústrias Reunidas Planaltina S/A (ou Frigorífico Planaltina), instalada a algumas quadras de distância da empresa dos Z. D. Costis. Diferentemente desta, o Frigorífico Planaltina foi construído com capitais familiares e de forma associativa, possibilitando que alguns funcionários virassem acionistas. Tal diferencial culminou em um rápido crescimento da empresa. No auge de sua produção, conformado entre os anos 1960 e 1970, o Frigorífico Planaltina superou o Z. D. Costi e conquistou o primeiro lugar em abate de suínos no estado do Rio Grande do Sul (TEDESCO et. al., 2005).

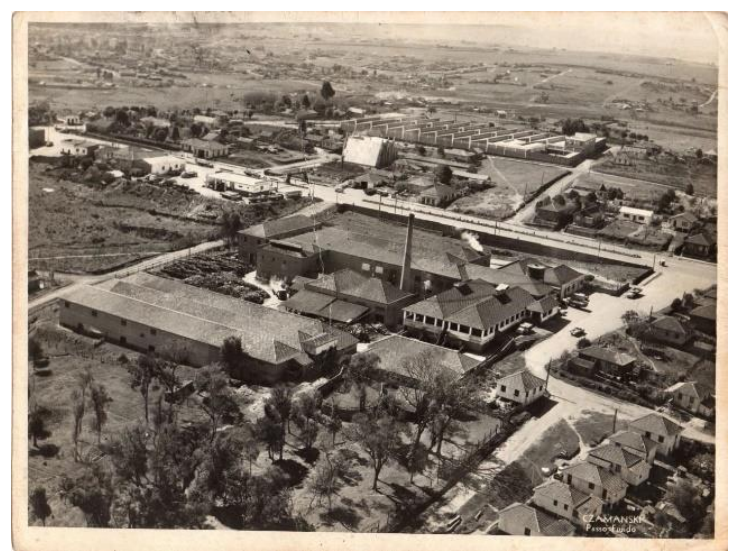

Figura 9: Imagem aérea do Frigorífico Planaltina (s/d), onde pode-se observar os prédios fabris ao centro e parte das casas operárias no segundo quadrante inferior direito. Fonte: Instituto Histórico Regional/PF (2020).

Os funcionários do Frigorífico Planaltina também se instalaram nos arredores da fábrica, seguindo o observado no caso anterior. A ideia dos acionistas era reter os
(Re)escrevendo a história da cidade: o mercado de terras de Passo Fundo (1920 - 1950) operários próximos aos prédios fabris. Foi então começaram a lotear terrenos que pertenciam à empresa com o intuito de vender aos funcionários. Dessa forma, foi se criando uma vila operária nos arredores do matadouro:

A ideia de instalar os operários próximos das indústrias foi uma estratégia dos empresários. O primeiro a fazer isso foi Zeferino Costi, proprietário do Z. D. Costi, que montou em torno de 40 casas operárias - que eram do frigorífico, mas que abrigavam os trabalhadores. A indústria Z. D. Costi ficava localizada, em partes, em um terreno que hoje abriga o Passo Fundo Shopping. O Planaltina fez diferente. Ele foi loteando pedaços de terras, que pertenciam ao frigorífico, e as pessoas foram comprando. Assim foi se criando uma vila operária ao redor (O NACIONAL, 2018, s/p).

A vila operária do Frigorífico Planaltina deu início ao desenvolvimento do Bairro Planaltina em uma área que, até a década de 1950, era destinada ao uso rural, pertencente ao bairro São Cristóvão. Após a instalação da referida vila, o poder público por meio da COHAB e com financiamento do Banco Nacional de Habitação (BNH), construiu mais 52 casas entre os anos de 1967 e 1968, que foram ocupadas, sobremaneira, pelos funcionários do Frigorífico (CAPELLA, 2007; FERRETTO, 2012). Atualmente, os prédios fabris do Frigorífico Planaltina estão em ruínas e sem utilização; fadados ao desaparecimento.

Quanto aos motivos da falência de ambos os frigoríicos, vale ressaltar o declínio da comercialização de banha ocorrido nos anos de 1980, em virtude da popularização do óleo de soja. Ademais, novas regras fitossanitárias modificaram os processos de produção das mercadorias e alguns problemas internos afetaram o funcionamento das empresas (O NACIONAL, 2018).

\section{Considerações finais}

Percebe-se que o processo de formação e transformação de Passo Fundo possui estreita relação com marcos históricos previamente identificados e analisados pela historiografia local. Dentre os principais marcos que contribuíram e/ou impulsionaram para formação e a modernização da cidade, podem-se citar: a Estrada de Tropas como o eixo estruturador da ocupação do território no início do século XIX; a construção da linha férrea, no ano de 1898; o Plano de Saturnino de Brito (1919) e o Plano de Expansão e Ordenamento da cidade (1953). 
Por outro lado, a partir dos levantamentos realizados, percebeu-se o anúncio da construção de uma série de novos loteamentos, equipamentos urbanos e vilas operárias que ajudaram a modificar - qualificando, embelezando e/ou modernizando -, de forma significativa a paisagem urbana passo-fundense, ao longo da primeira metade do século XX. Nesse período, foram construídos pelo menos 10 novos loteamentos privados e 3 vilas operárias, que deram origem e/ou impulsionaram o crescimento a importantes bairros da cidade.

Sendo assim, percebe-se que a historiografia local vem se concentrando, nos últimos anos, nos estudos relativos à expansão da malha urbana de Passo Fundo, essencialmente após a metade do século $\mathrm{XX}$, a partir da criação e outorga do mencionado Plano de 1953. É factível afirmar que parte significativa, senão a maioria, dos grandes loteamentos, àquela época periféricos, de Passo Fundo surgiu após os anos de 1950, conforme os supracitados estudos colocam. Entretanto, sugerese um olhar mais cauteloso para o mercado de terras que foi estruturado naquele momento, sobretudo, a partir de interesses privados, que passou a expandir e transformar significativamente a malha urbana passo-fundense após a década de 1920, principalmente em virtude da dimensão desses loteamentos e vilas operárias, bem como da importância atual dos bairros nos quais estão inseridos.

\section{Agradecimentos}

À Coordenação de Aperfeiçoamento de Pessoal de Nível Superior (CAPES) e à Fundação Meridional pelas bolsas concedidas.

\section{Referências}

ALMEIDA, Caliane Christie Oliveira de. Habitação social: origens e produção (Natal, 1889-1964). 2007. Dissertação (Mestrado em Teoria e História da Arquitetura e do Urbanismo) - Escola de Engenharia de São Carlos, Universidade de São Paulo, São Carlos, 2007.

AVENIDA Mauá. O Nacional, jun. 1929, n.582.

CAPELLA, Tereza Edite. Indústrias Planaltina Ltda e o Bairro Planaltina de Passo Fundo - RS, estudo de relação de dependência. Monografia (Graduação em História) - Universidade de Passo Fundo, Passo Fundo 2007.
(Re)escrevendo a história da cidade: o mercado de terras de Passo Fundo (1920 - 1950) CORREIA, Telma de Barros. De vila operária a cidade-companhia: as aglomerações criadas por empresas no vocabulário especializado e vernacular. Revista Brasileira de Estudos Urbanos e Regionais, [S.I.], n. 4, p. 83, 2001.

DAL AGNOL, Bruna. Os processos de formação e transformação das cidades de Serafina Corrêa, Casca e do Distrito de Evangelista: Paisagem, Identidade e Percepção. 2018. Dissertação (Mestrado em Arquitetura e Urbanismo) - Faculdade Meridional, Passo Fundo, 2020.

DINIZ, Pedro Henrique Carretta; ALMEIDA, Caliane Christie Oliveira de. Passo Fundo Shopping e os reflexos para uma cidade média no noroeste do Rio Grande do Sul. Revista de Arquitetura IMED, Passo Fundo, v. 6, n. 2, p. 149-165, dez. 2017. ISSN 2318-1109. Disponível em: https://seer.imed.edu.br/index.php/arqimed/article/view/2188/1656. Acesso em: 12 set. 2019.

DINIZ, Pedro Henrique Carretta; ALMEIDA, Caliane Christie Oliveira de. HABITAÇÃO OPERÁRIA EM PASSO FUNDO (RS): FRIGORÍFICO Z. D. COSTI E FRIGORÍFICO PLANALTINA. In: XIV Mostra de Iniciação Científica e Extensão Comunitária e XIII Mostra de Pesquisa de Pós-Graduação IMED, 2018, Passo Fundo. Anais [...]. Passo Fundo: IMED, 2018. s/p.

FERRETTO, Diego. Passo Fundo: estruturação urbana de uma cidade média gaúcha. 2012. Dissertação (Mestrado em Planejamento Urbano e Regional) - Faculdade de Arquitetura e Urbanismo, Universidade de São Paulo, São Paulo, 2012.

GOSCH, L. R. M. Passo Fundo, de Saturnino de Brito ao Mercosul - projetos e imagens urbanas. (Dissertação). Rio de Janeiro: FAU/UFRJ, 2002.

GUIA GERAL DE PASSO FUNDO. Passo Fundo: Tipografia Nehls, 1941.

INSTITUTO BRASILEIRO DE GEOGRAFIA E ESTATÍSTICA - IBGE. Censo Demográfico. Passo Fundo/RS, 2010. Disponível em: < http://cidades.ibge.gov.br/xtras/perfil.php?codmun=431410/ >. Acesso em 30 abr. 2020.

JUNIOR, Dirceu Piccinato. Saturnino de Brito e o projeto de abastecimento de água para a cidade de Passo Fundo/RS. Cadernos de Arquitetura e Urbanismo, v. 25, n. 36, 2018. 
JUNIOR, Dirceu Piccinato; ALMEIDA, Caliane Christie Oliveira de. KUJAWA, Henrique Aniceto. $O$ ideário urbano de Saturnino de Brito e o plano de melhoramentos para a cidade de Passo Fundo/RS. Revista Oculum Ensaios, v.17, n.1, 2020.

MATADOURO público. O Nacional, out. 1926, n.160.

MENÇÃO empresarial: Z. D. Costi \& Cia. Ltda. O Nacional, dez. de 1979, p.14.

MINISTÉRIO da Educação e Saúde. Projeto e Relatório de Passo Fundo. Rio de Janeiro: Imprensa Nacional, 1943.

MIRANDA, Fernando B. Severo; MACHADO, Ironita P. Passo Fundo: Presentes da Memória. Rio de Janeiro: MM Comunicações, 2005.

NOVAS Villas. O Nacional, mai. 1929, n.549.

NOVO Código de Posturas. O Nacional, jan. 1925, n.1.

PARIZZI, Marilda Kirst. Passo Fundo: sua história e evolução. Passo Fundo: Berthier, 1983.

PASSAMANI, Lzandra Hoffmann. Pobreza urbana: as condições de habitação popular no município de Passo Fundo/RS. 2012. Dissertação (Mestrado em Serviço Social) - Pontifícia Universidade Católica do Rio Grande do Sul, Porto Alegre, 2012. RELATÓRIO DO PREFEITO MÁRIO MENEGAZ - 1969. Passo Fundo: O Nacional Editora, 1969.

SEÇÃO de obras. O Nacional, mai. 1926, n.86.

TEDESCO, João Carlos et. al. Agroindústrias, frigoríficos e cooperativismo. Porto Alegre: EST, 2005.

TEDESCO, João Carlos; A Gare e o Trem em Passo Fundo: sinergias econômicas - 1898 - 1978. Porto Alegre: Editora \& Livraria Frei Rovílio Ltda, 2015.

TEDESCO, João Carlos; SOUZA, Sirlei de Fátima. Frigoríficos e olarias em Passo Fundo: dinâmicas industriais em sinergias - 1940 a 1980. Erechim: All Print Varella, 2016.
Pedro Henrique Carretta Diniz e Caliane Christie Oliveira de Almeida

(Re)escrevendo a história da cidade: o mercado de terras de Passo Fundo (1920 - 1950) TIMM, Juliane Aimé. Habitações operárias no Brasil: arquitetura e urbanismo da habitação social na primeira metade do século XX. Dissertação (Mestrado em Arquitetura) - Faculdade de Arquitetura, Universidade Federal do Rio Grande do Sul, Porto Alegre, 2015.

VILLA Cruzeiro. O Nacional, set. 1928, n.321.

VILLA Petrópolis. O Nacional, nov. 1928, n.382.

VILLA Rodrigues. A Voz da Serra, out. 1920, n.230.

VILLA Rodrigues. O Nacional, jul. 1927, n.260.

WICKERT, Ana Paula. Nos caminhos da ferrovia: A arquitetura ferroviária da linha Tronco Norte Gaúcha, 1883-1920. Dissertação (Mestrado em Arquitetura e Urbanismo) - Faculdade de Arquitetura e Urbanismo, UFBA, 2002. 